\title{
What happens after the catchment caught the storm? Hydrological processes at the small, semi-arid Weatherley catchment, South-Africa
}

\author{
S. Uhlenbrook ${ }^{1}$, J. Wenninger ${ }^{2}$, and S. Lorentz ${ }^{3}$ \\ ${ }^{1}$ UNESCO-IHE Institute of Water Education, P.O. Box 3015, 2601 DA Delft, The Netherlands \\ ${ }^{2}$ University of Freiburg, Institute of Hydrology, Fahnenbergplatz, 79098 Freiburg, Germany \\ ${ }^{3}$ University of KwaZulu-Natal, School of Bioresources Engineering and Environmental Hydrology, Pietermaritzburg, \\ South-Africa
}

Received: 24 October 2004 - Accepted: 18 May 2005 - Published: 11 July 2005

\begin{abstract}
The knowledge of water flow pathways and residence times in a catchment are essential for predicting the hydrological response to a rain storm event. Different experimental techniques are available to study these processes, which are briefly reviewed in this paper. To illustrate this, recent findings from the Weatherley catchment a $1.5 \mathrm{~km}^{2}$ semiarid headwater in South-Africa, are reported in this paper. Beside classical hydrometric measurements of precipitation and runoff different experimental techniques were applied to explore flow paths (i.e. soil moisture and groundwater measurements, natural tracers, and 2-D electrical resistivity tomographies (ERT)).
\end{abstract}

\section{Introduction}

After a "storm was caught" by a catchment (cf. the symposium is entitled "Catching the storm") a flood is generated. The extent of the flood depends on different hydrological processes within in the catchment which are not understood well enough (Bonell, 1998). It was also observed that different processes can dominate the hydrological response of a catchment depending on the specific circumstances, as for instance, spatio-temporal distribution of precipitation, antecedent moisture conditions etc. However, the first order controls of the different processes are still in the scientific debate and an unifying and generalized theory of catchment functioning is still missing (McDonnell, 2003). This in particular the case if subsurface flow processes dominate the hydrological response.

Hydrological processes within a catchment define how precipitation reaches the catchment outlet, how long water

Correspondence to: S. Uhlenbrook

(s.uhlenbrook@unesco-ihe.org) is stored in surface water, soil water and groundwater systems, and what hydrochemical composition these sources have. To investigate these processes, different types of field studies have been conducted: (i) Comparisons of the hydrological responses of headwater basins were carried out (e.g. Jones, 2000). (ii) Soil physical and hydrometrical studies, using tensiometers and piezometers, were executed at the plot scale (e.g. McDonnell, 1990). (iii) Sprinkling experiments at hillslopes, often in combination with tracer tests, were conducted (e.g. Mosley, 1982). (iv) Geophysical measurements proved useful to explore subsurface soil properties, which are crucial for processes (e.g. Sherlock et al., 2000). (v) Finally, the use of isotopic tracers (e.g. Buttle, 1994) in combination with hydrochemical tracers (e.g. Anderson et al., 1997) helped to gain further insights into processes, in particular into the flowpaths, residence times of water and the mixing of different runoff components. Each method has its own strengths and shortcomings concerning costs and the temporal and spatial scale at which they can be used. However, these experiments form the basis for the development and parameterization of process-based hydrological models (e.g. Leavesley et al., 1995; Uhlenbrook et al., 2004). Models offer one way to regionalize small-scale knowledge to larger scales (Becker, 1992) and enable the researcher to make predictions at catchment scale.

The objective of this paper is to summarize recent investigations of runoff generation processes in a small, semi-arid catchment in South-Africa. In particular, the use of a new geophysical technique, i.e. 2-D electrical resistivity tomography, to explore sub-surface flowpaths is demonstrated. Due to the limitations in the lengths of the paper, the part of the process-oriented modeling and reduction of prediction uncertainty (presented in the oral lecture at the symposium) is skipped here. These results have been published in Uhlenbrook and Sieber (2005). 


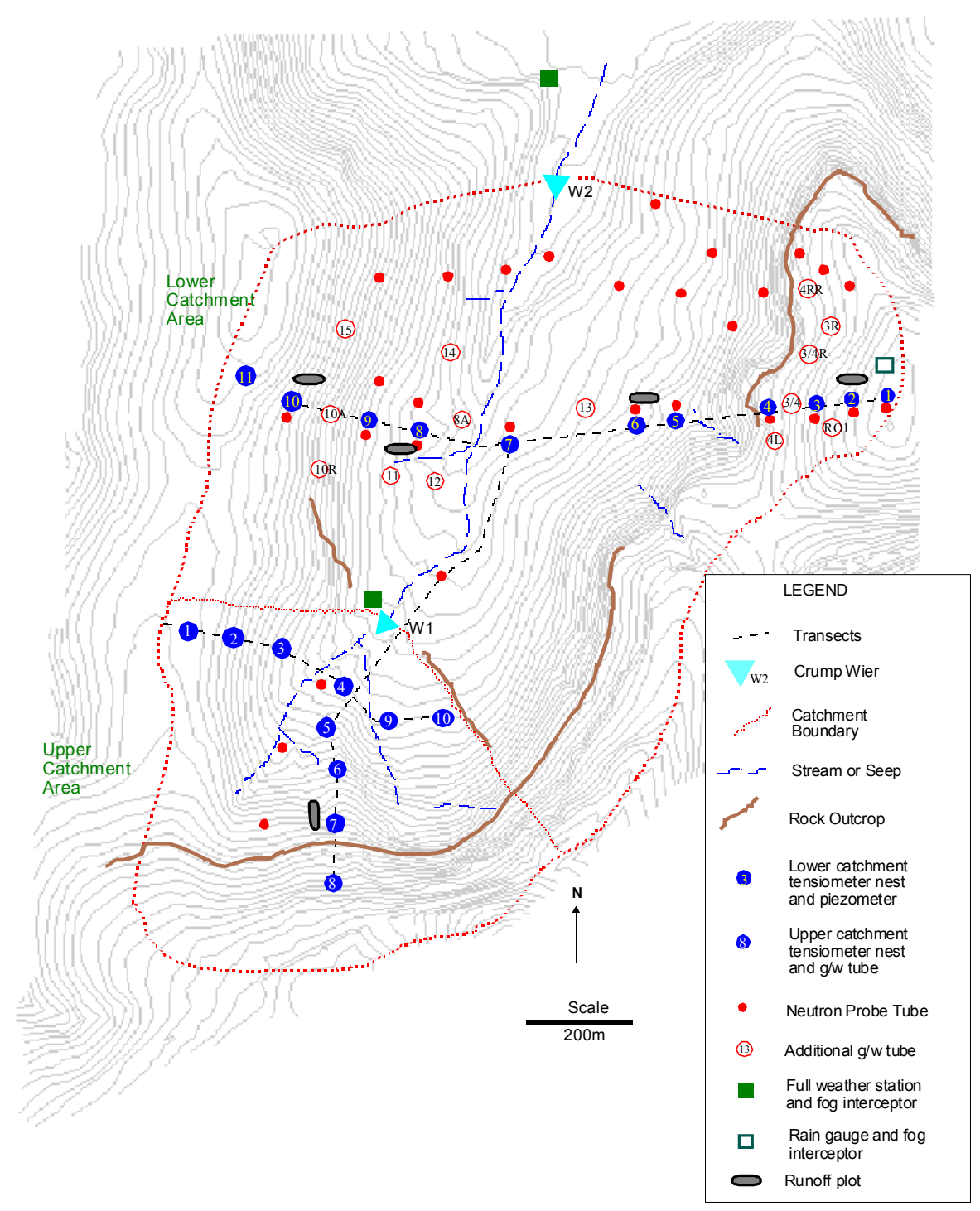

Fig. 1. The experimental Weatherley catchment and its instrumentation network (adapted from Lorentz et al., 2004).

\section{Material and methods}

\subsection{Study site and instrumentation network}

The Weatherley catchment is a $1.5 \mathrm{~km}^{2}$ research catchment located in the Umzimvubu basin of the northern Eastern Cape Province, South Africa. The elevation ranges from $1228 \mathrm{~m}$ to $1337 \mathrm{~m}$ a.m.s.l.; the slopes are gentle except for areas near the bedrock outcrops in the western and southern part of the catchment (Fig. 1). The land use is mainly Highlands Sourveld grassland. Wetland conditions exist along the entire reach of the stream and range in width from 100 to $400 \mathrm{~m}$. The soils are characterized by varying degree of wetness and colour and include red and yellow apedal mesotrophic soils as well as neocutanic and hydromorphic soils. The mean annual precipitation amounts to $740 \mathrm{~mm}$, and the mean annual class A-pan evaporation was estimated as $1488 \mathrm{~mm}$ (Esprey, 1997). Average daily temperatures range from $11^{\circ} \mathrm{C}$ in the winter to $20^{\circ} \mathrm{C}$ in the summer. Precipitation has a large seasonality; more than $80 \%$ falls in the summer period from November to March.

The instrumentation network includes two transects with nests of automatic recording tensiometers and groundwater wells as well as neutron probe access tubes in an upper and lower sub-catchment, each served by a crump weir (Fig. 1). It was established in 1995 in order to assess the impacts of afforestation in a representative catchment in the Molteno-Elliot sedimentary formations (sandstone and mudstone). The research catchment and the experimental findings have been described in detail in Lorentz (2001) and Lorentz et al. (2004). 


\subsection{2-D electrical resistivity tomography (ERT)}

The subsurface resistivity is mainly related to various geological and hydrological parameters: the lithology (rock and grain sizes, porosity, mineralogy), the fluid content (solutes) and the degree of water saturation. Electrical resistivity surveys have been made for decades in hydrogeology or geotechnical investigations; more recently it has been used to solve problems in environmental hydrology. The determination of the resistivity goes back to Ohm's law, which describes the relations between the current density, the electrical field (voltage) and the resistivity. For further details see e.g. Loke (2003).

For mapping the electrical resistivity of the subsurface the classical method is injecting current into the ground through two current electrodes and measuring the resulting voltage difference at two potential electrodes. In the classical 1-D method the vertical resistivity distribution at the midpoint of the electrode array is measured by increasing the distance of the current electrodes to obtain information about the resistivity in larger depths. The major limitation of the vertical sounding method is that the provided values of the resistivity are only point information that is problematic if lateral heterogeneities exist, and these are dominant at hillslope hydrology problems. Therefore 2-D surveys using recent developments of multi-electrode resistivity surveying instruments and fast inversion software come into play. However, only very few examples have been reported in the literature thus far.

The resistivity surveys were carried out using the Syscal Junior Switch System with 24 electrodes and two multi-core cables (maximal spacing between two electrodes $5 \mathrm{~m}$ ). The lower transect (Fig. 1), comprising the nests 1-11, runs EastWest, from the crest of the eastern slope down into the wetland, across the stream and up the western slope was investigated in further detail. Along this transect 2-D electrical imaging surveys were carried out with the aim of improving the characterization of the hydrological processes in the shallow subsurface.

The electrodes were set along the hillslope transects, and a roll along procedure (installing half of the electrodes at the end of the transect as soon as the first half of the electrodes are free) enable one to investigate transects of several $100 \mathrm{~m}$ with a spacing between the electrodes of only $2 \mathrm{~m}$. This provided results in an appropriate spatial resolution to a depth of 5-7 m. In a 2-D survey the different pairs of the 24 electrodes that serve either as current or potential electrodes are used, and the distance between the electrodes is varied systematically. The 2-D Wenner configuration was used as the electrical array. The measured pseudosections (apparent resistivity) were processed with a 2-D inverse numerical modeling technique (software: RES2DINV) to give the estimated true resistivities of the subsurface (for further details see Loke, 2003).

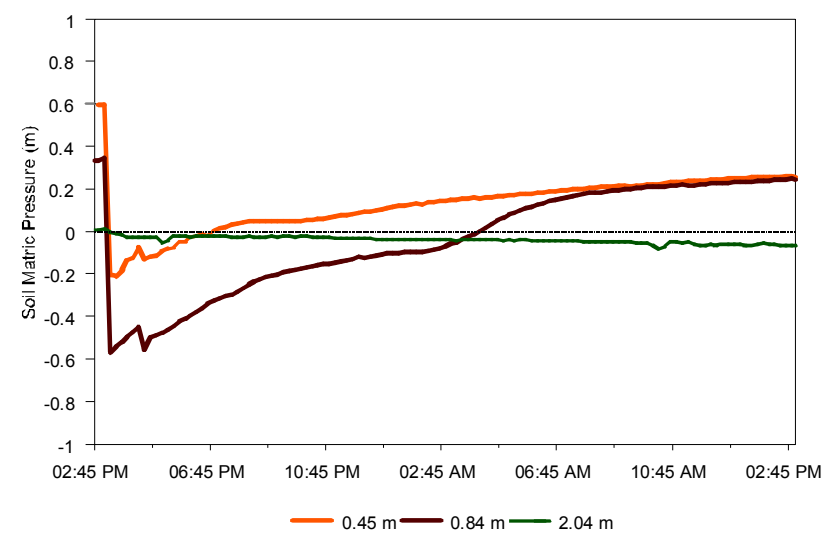

Fig. 2. A typical record of matric pressure heads at station 2 at the investigated transect in the lower catchment (adapted from Lorentz, 2001).

\section{Results}

\subsection{Tensiometer data}

The study of tensiometer records nests located along the transect are useful in interpreting the storage and movement of water on the respective sections of the hillslope. Several events have been analyzed in detail (Lorentz, 2001); a typical example of the tensiometer record for nest 2 is shown in Fig. 2. The matric pressure heads at the start of the record in the upper two tensiometers at $0.45 \mathrm{~m}$ and $0.84 \mathrm{~m}$ below the surface, are $0.6 \mathrm{~m}$ and $0.35 \mathrm{~m}$ respectively, indicating relatively moist conditions near the surface. The positive value of the matric pressure head reflects the degree of suction in the soil water. High values of the matric pressure heads represent dry soils and low values wet soils. The matric pressure head at $2.04 \mathrm{~m}$ depth is $0 \mathrm{~m}$, indicating a water table at this depth. With the onset of a rain event after 2:45 p.m., the matric pressure heads in the upper two tensiometers drop rapidly, indicating that the soil profile is wetting up. In fact the matric pressure heads drop below zero. This negative value for matric pressure head means that the soil water pressure is positive and that a phreatic surface has moved up above the ceramic. This phreatic surface or water table has maximum heights of $0.2 \mathrm{~m}$ and $0.6 \mathrm{~m}$ above the ceramics at $0.45 \mathrm{~m}$ and $0.84 \mathrm{~m}$ depth, respectively. These values coincide with a phreatic surface which is $0.25 \mathrm{~m}$ below ground level. However, the matric pressure head at the depth $2.04 \mathrm{~m}$ change only slightly (maximum water table height is $0.05 \mathrm{~m}$ ), and certainly does not reflect the development of the phreatic surface suggested by the upper tensiometers.

Hence, it is clear that the upper two tensiometers are recording the temporary build up of a perched water table which develops due to a layer which inhibits rapid drainage to the lower and more sustained water table, perched on the bedrock in a depths of about $2 \mathrm{~m}$. This phenomenon could also be explained by the cessation of macro pores at approximately $1 \mathrm{~m}$ below the surface. Rapidly transferred water, 


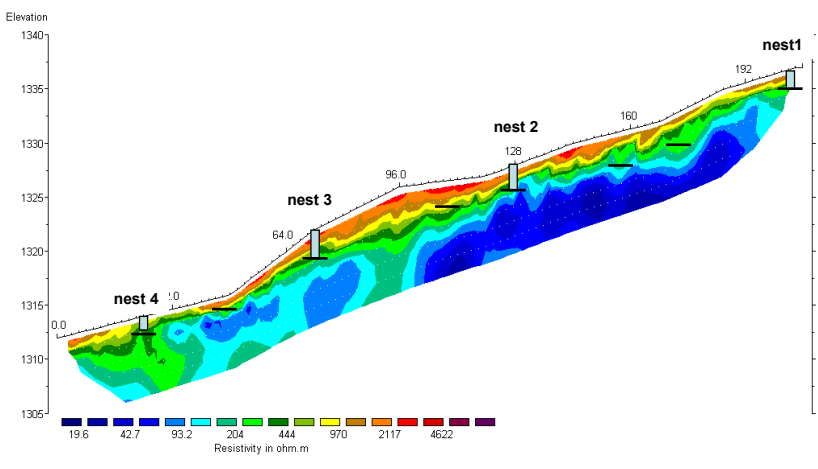

Fig. 3. Results of the 2-D electrical imaging survey at the investigated hillslope using a Wenner 2-D configuration with electrode spacing of $2 \mathrm{~m}$ as electrical array. The first and last electrode is located at 0 and $208 \mathrm{~m}$, respectively (vertical exaggeration by the factor 3). The numbering of the nests corresponds to Fig. 1. The horizontal black lines indicate the depths of the bedrock determined by augering.

arriving at this level via the macro pores, backs up on the slow conducting soil matrix below and forms this perched water table. The upper perched water table is quickly drained as the tensiometer signals in the upper horizons reflect unsaturated conditions again, some $12 \mathrm{~h}$ after the event. However the deeper water table continues to rise as indicated be the continued gradual decrease in matric pressure head of the tensiometer at $2.04 \mathrm{~m}$ below ground surface.

\subsection{2-D electrical imaging surveys using ERT}

This paper reports the results of the geoelectrical investigations at the upper eastern part of the transect (nests 1-4). The large spatial heterogeneity of the subsurface resistivity became obvious (Fig. 3). Measurement of the groundwater depth at the four nests allowed for the determination of the resistivity value that differentiate between saturated and unsaturated parts in the soil (about $950 \Omega \mathrm{m}$; yellow color). At the top layer relatively high resistivities (above $2000 \Omega \mathrm{m}$ ) are evident in the upper part and at the toe of the hillslope. A saturated near surface layer existed between 10-30 m, which could be also observed during the field measurements (seeping groundwater). Above $30 \mathrm{~m}$ from the toe, the groundwater table was observed at a depth of about $1.2 \mathrm{~m}$ below the surface, indicating that the water body is located in the soil above the bedrock.

The depth of the sandstone bedrock had been estimated by augering and confirmed by ground penetrating radar measurement (Lorentz, 2001). The investigations demonstrate that resistivity values of less than $300 \Omega \mathrm{m}$ mark the interface between the bedrock and the soil material (Fig. 3). These values agree with the values reported by Loke (2003). The irregular bedrock topography determined by the ground penetrating radar measurement could be confirmed with the geophysical method. Detailed investigations perpendicular to the transect (not reported in further detail here) in high res-

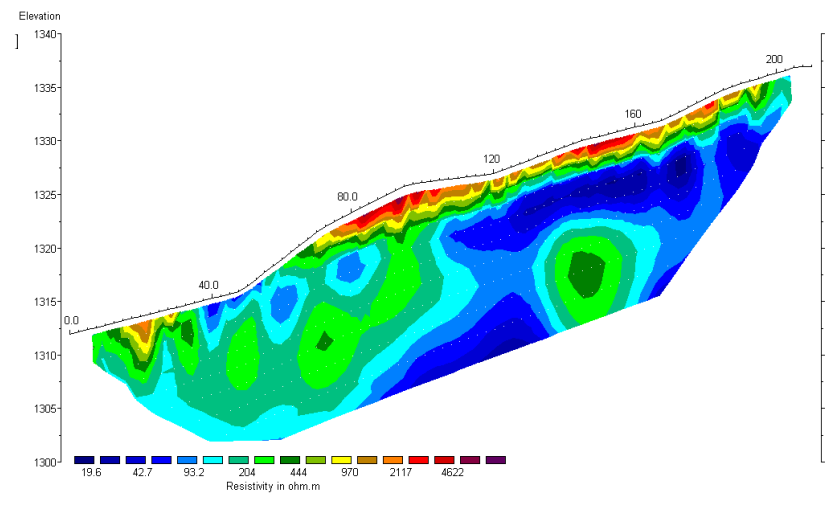

Fig. 4. Results of the 2-D electrical imaging survey using ERT at the investigated hillslope using a Wenner 2-D configuration with electrode spacing of $5 \mathrm{~m}$ as electrical array (only difference to Fig. 2).

olution with $0.5 \mathrm{~m}$ electrode spacing, indicated far less heterogeneity perpendicular to the slope. This provides some confidence in the studied transect being representative of this hillslope.

The resistivity values of the bedrock vary between $<20$ $300 \Omega \mathrm{m}$ indicating different water contents in this fissured aquifer. A repetition of the measurements using a larger electrode spacing of $5 \mathrm{~m}$ (Fig. 4) allowed a deep penetration of the measurements at the expense of a lower resolution. The findings at the shallow subsurface of less than $5 \mathrm{~m}$ could be confirmed. Of particular interest is the irregular pattern of the bedrock resistivity at a depth of 5-18 m. This can be interpreted as water filled fractures surrounded by a saturated sandstone matrix with reasonable porosity.

\section{Summary and conclusions}

Below an unsaturated zone a perched groundwater aquifer is situated in the soil cover above the bedrock. The soil cover/bedrock contact has an irregular topography. This shallow groundwater seeps out at the toe of the hillslope. Within the bedrock, a fissured sandstone aquifer is established, which gets recharged from the perched groundwater above. This groundwater apparently partly contributes to the groundwater seepage face at the toe, but also deep groundwater circulations became obvious. The latter seems to be connected to the regional groundwater system. This process description confirms that which has been derived from perched groundwater and tensiometer observations and adds insight into the deeper groundwater system. In general, the measurement of soil water contents using tensiometers, neutron probes and TDR measurements as well as groundwater tables along the transect enabled to understanding water storage and movement at the event and seasonal time scale. Thus, lateral subsurface flow pathways could be detected

The ERT surveys provided detailed images of the subsurface resistivity of the hillslope. Together with other experimental data sets, i.e., soil moisture, depth of water level 
and depth of bedrock, the patterns of the subsurface resistivity were very useful to gain further insights into the hydrological processes. In particular, major source of areas of runoff could be mapped and the occurrence and recharge of deeper groundwater became evident. As the ERT investigations were executed in February near the end of the rainy season, and probably the wettest time of the year, a repetition during the dry winter period would be interesting. This would allow for further insights into the location of groundwater bodies during dry weather flow, and consequently, into the generation of low flows.

To conclude, the determination of source areas, flow pathways and residence times of water and solutes is crucial for the characterization of stream flow dynamics (i.e. floods and low flows) and water quality. The best and most reliable results can be obtained when different field methods are applied at the same test site, as each method has its shortcomings and limitations. In addition to the experimental investigation modeling studies should be carried out simultaneously to test hypotheses about process behavior and at the hillslope and catchment scale.

Acknowledgements. The ERT measurements were financed by a grant for especially talented young scientists by the state of BadenWürttemberg, Germany (Eliteförderprogramm für Postdoktoranden Baden-Württemberg). The research at the Weatherley catchment was supported by the South-African Water Research Commission (WRC) and Mondi Forest.

Edited by: L. Ferraris

Reviewed by: anonymous referees

\section{References}

Anderson, S. P., Dietrich, W. E., Montgomery, D. R., Torres, R., Conrad, M. E., and Loague, K.: Subsurface flow paths in a steep, unchanneled catchment, Water Resour. Res., 33(12), 2637-2653, 1997.

Becker, A.: Methodische Aspekte der Regionalisierung, Regionalisierung hydrologischer Parameter, Wiley-VCH, Weinheim, 1992.

Bonell, M.: Selected challenges in runoff generation research in forests from the hillslope to headwater drainage basin scale, J. of Am. Wat. Res. Ass., 34(4), 765-785. 1998.

Buttle, J. M.: Isotope hydrograph separations and rapid delivery of pre-event water from drainage basins, Progress in Physical Geography, 18, 16-41, 1994.
Esprey, L. J.: Hillslope experiments in the North Eastern Cape to measure and model subsurface flow processes, Unpublished M.Sc. dissertation, Department of Agric. Eng. University of Natal, Pietermaritzburg, South Africa, 1997.

Loke, H. M.: Tutorical: 2-D and 3-D electrical imaging surveys, 134 pages, www.geoelectrical.com, 2003.

Lorentz, S.: Hydrological Systems Modelling Research Programme: Hydrological Processes. Phase I: Processes Definition and Database, Report to the Water Research Commission on the project: Hydrological Systems Modelling Research Programme: Processes Research, WRC Report 637/1/01, Water Research Commission, Pretoria, South Africa, 2001.

Lorentz, S., Thornton-Dibb, S., Pretorius, J., and Goba, P.: Hydrological Systems Modelling Research Programme: Hydrological Processes, Phase II: Quantification of Hillslope, Riparian and Wetland Processes, Report to the Water Research Commission on the project: A Field Study of Two and Three Dimensional Processes in Hillslope Hydrology for Better Management of Wetlands and Riparian Zones and Experimental and Laboratory Measurements of Soil Hydraulic Properties, WRC Report K5/1061 and K5/1086, Water Research Commission, Pretoria, South Africa, 2004.

Jones, J. A.: Hydrologic processes and peak discharge response to forest removal, regrowth, and roads in 10 small experimental basins, western Cascades, Oregon, Water Resour. Res., 36, 9, 2621-2642, 2000.

Leavesley, G. H. and Stannard, L. G.: The precipitation - runoff modelling system - PRMS, in: Computer Models of Watershed Hydrology, edited by: Singh, V. P., Water Resources Publications, Fort Collins, Colorado, USA, 281-310, 1995.

McDonnell, J. J.: A Rationale for old water discharge through macropores in a steep, humid catchment, Water Resour. Res., 26 , 2821-2832, 1990.

McDonnell, J. J.: Where does water go when it rains? Moving beyond the variable source area concept of rainfall-runoff response, Hydrological Processes, 17, 9, 1869-1875, 2003.

Mosley, M. P.: Subsurface flow velocities through selected forest soils, south island, New Zealand, J. Hydrol., 55, 65-92, 1982.

Sherlock, M. D., Chappell, N. A., and McDonnell, J. J.: Effects of experimental uncertainty on the calculation of hillslope flow paths, Hydrological Processes, 14(14), 2457-2471, 2000.

Uhlenbrook, S., Roser, S., and Tilch, N.: Hydrological process representation at the meso-scale: The potential of a distributed, conceptual catchment model, J. Hydrol., 291, 278-296, 2004.

Uhlenbrook, S. and Sieber, A.: On the value of experimental data to reduce the prediction uncertainty of a process-oriented catchment model, Environmental Modeling and Software, 20, 19-32, 2005. 